\title{
ULAM-HYERS STABILITY FOR MATRIX-VALUED FRACTIONAL DIFFERENTIAL EQUATIONS
}

\author{
ZhanPEng YANG, WenjuAn Ren AND TiAnZHou Xu
}

\begin{abstract}
In this paper, some Ulam-Hyers stability results for matrix-valued fractional differential equations are obtained. We also establish some sufficient conditions for the stability of matrix-valued fractional differential equations.
\end{abstract}

Mathematics subject classification (2010): 34A15, 34D20, 39B82, 47L25.

Keywords and phrases: Mittag-Leffler matrix, matrix-valued fractional differential equation, UlamHyers stability.

\section{REFERENCES}

[1] A. A. Kilbas, H. M. Srivastava And J. J. Trujillo, Theory and Application of Fractional Differential Equations, Elsevier, New York.

[2] K. B. Oldham And J. Spanier, The Fractional Calculus, Acadmic Press, New York.

[3] D. Matignon, Stability results for fractional differential equations with applications to control processing, Proceedings of the IMACS-SMC 2, 1 (1996), 963-968

[4] Y. D. MA, J. G. LU AND W. D. ChEN, Robust stability and stabilization of fractional order linear systems with positive real uncertainty, ISA Transactions 53, 2 (2014), 199-209.

[5] W. H. Deng, C. P. Li AND J. H. LÜ, Stability analysis of linear fractional differential system with multiple time delays, Nonlinear Dynamics 48, 4 (2007), 409-416.

[6] Y. Li, Y. Q. Chen AND I. Podlubny, Mittag-Leffler stability of fractional order nonlinear dynamic systems, Automatica 45, 8 (2009), 1965-1969.

[7] Y. LI, Y. Q. Chen And I. Podlubny, Stability of fractional-order nonlinear dynamic systems: Lyapunov direct method and generalized Mittag-Leffler stability, Computers and Mathematics with Applications 59, 5 (2010), 1810-1821.

[8] H. DelaVari, D. Baleanu AND J. SADATI, Stability analysis of Caputo fractional-order nonlinear systems revisited, Nonlinear Dynamics 67, 4 (2012), 2433-2439.

[9] S. Bilal, A. Abdullah and B. Alagoz, A numerical investigation for robust stability of fractional-order uncertainsystems, ISA Transactions 53, 2 (2014), 189-198.

[10] S. M. Ulam, A Collection of Mathematical Problems, Interscience Publishers, New York.

[11] D. H. HYERS, On the stability of the linear functional equation, Proceedings of the National Academy of Sciences of the United States of America 27, 27 (1941), 222-224.

[12] T. AOKI, On the stability of the linear transformation in Banach spaces, Journal of the Mathematical Society of Japan 1950, 2 (1950), 64-66.

[13] T. M. RAssiAs, On the stability of the linear mapping in Banach spaces, Proceedings of the American Mathematical Society 72, 2 (1978), 297-300.

[14] J. M. RASSIAS, On approximation of approximately linear mappings by linear mappings, Journal of Functional Analysis 46, 1 (1982), 126-130.

[15] T. Z. XU, J. M. Rassias AND W. X. XU, Stability of a general mixed additive-cubic functional equation in non-Archimedean fuzzy normed spaces, Journal of Mathematical Physics 51, 9 (1982), $1-19$.

[16] Z. P. Yang, T. Z. XU AND M. QI, Ulam-Hyers Stability for Fractional Differential Equations in Quaternionic Analysis, Advances in Applied Clifford Algebras 26, 1 (2016), 1-10. 
[17] T. Z. XU, Z. P. YANG AND J. M. RAssias, Direct and fixed point approaches to the stability of an $A Q$-functional equation in non-Archimedean normed spaces, Journal of Computional Analysis and Applications 17, 4 (2014), 697-706.

[18] S. M. JUng AND T. M. RAssias, A linear functional equation of third order associated to the Fibonacci numbers, Abstract and Applied Analysis 2014, 2 (2014), 1-7.

[19] S. M. Jung, D. Popa AND T. M. Rassias, On the stability of the linear functional equation in a single variable on complete metric groups, Journal of Global Optimization 59, 1 (2014), 165-171.

[20] S. M. JUnG, On the Hyers-Ulam stability of the functional equations that have the quadratic property, Journal of Mathematical Analysis and Applications 222, 1 (1998), 126-137.

[21] J. R. WANG, L. L. LÜ AND Y. ZHOU, New concepts and results in stability of fractional differential equations, Communications in Nonlinear Science and Numerical Simulation 17, 6 (2012), 2530-2538.

[22] J. R. WANG, Y. ZHOU AND M. FEC KAN, Nonlinear impulsive problems for fractional differential equations and Ulam stability, Computers and Mathematics with Applications 64, 10 (2012), 33893405.

[23] J. R. WANG, Y. Zhou AND M. FeC KAn, Ulam-Hyers-Mittag-Leffler stability of fractional order delay differential equations, Optimization 63, 8 (2014), 1181-1190.

[24] Z. H. WANG, Functional inequalities in matrix Banach spaces, Journal of Mathematical Inequalities 11, 1 (2017), 87-97.

[25] J. R. LeE, Stability of Functional Equations in Matrix Random Normed Spaces: A Fixed Point Approach, Results in Mathematics 66, 1 (2014), 99-127.

[26] J. R. LEE, Stability of functional inequalities in matrix random normed spaces, Journal of Inequalities and Applications 2013, 1 (2013), 1-12.

[27] M. CAPUTO, Linear models of dissipation whose Q is almost frequency independent part II, Geophysical Journal International 13, 5 (2007), 529-539.

[28] Z. OdiBAT, Analytic study on linear systems of fractional differential equations, Computers and Mathematics with Applications 59, 3 (2010), 1171-1183.

[29] I. A. Rus, Picard operators and applications, Scienticae Mathematicae Japonocae 58, 1 (2003), 191219. 